\title{
Atrévete a ironizar: propuesta para la enseñanza de la prosodia y la kinesia de la ironía
}

\author{
JULIO TORRES SOLER \\ Universidad de Alicante \\ jts30@alu.ua.es \\ GuAdALUPe CARBAJO GARCía \\ Universidad de Alicante \\ gcg42@alu.ua.es \\ María del Pilar Aparicio del Olmo \\ Universidad de Alicante \\ mdpa16@alu.ua.es
}

Resumen: La ironía es un fenómeno complejo que puede suponer un verdadero reto para los aprendientes de Español como Lengua Extranjera (ELE). Sin embargo, los enunciados irónicos presentan marcas e indicadores que pueden facilitar al estudiante su aprendizaje. El objetivo de este trabajo es ofrecer una propuesta didáctica para enseñar las marcas prosódicas y kinésicas de la ironía, ante la falta de recursos que aborden estos rasgos. Para ello, nos basamos en los parámetros del método verbo-tonal y adoptamos un enfoque fonocognitivo, que abarca tanto la percepción como la producción de enunciados irónicos. Con la ayuda del programa informático PRAAT, de una metáfora visual y de diversos materiales audiovisuales, los estudiantes serán capaces de reconocer las particularidades del patrón entonativo de la ironía (subida de la fo, aumento de la duración), así como sus indicadores kinésicos (guiños, miradas, sonrisas, etcétera).

Palabras clave: ironía, prosodia, kinesia, ELE, método verbo-tonal.

\section{How to be ironic: A proposal for teaching irony's prosodic and kinesic features}

Abstract: Irony is a complicated matter, which can present a considerable challenge for a Spanish as a Second Language (SSL) student. Nevertheless, ironic statements have a number of distinctive characteristics that can allow for and potentially facilitate learning. Due to the lack of resources in this field, the purpose of this paper is to propose a lesson plan to teach the prosodic and kinesic features of irony. This lesson plan was based on the principals of the Verbotonal Method and takes a phono-cognitive approach to the perception and production of ironic statements. Aided by the computer program PRAAT, a visual metaphor and other audiovisual materials, the students should be able to recognise the characteristics of the ironic intonation (a rise of the f0, prolonged statements) and its kinesic features (winks, gazes, grins, etcetera).

Key words: irony, prosody, kinesics, SSL, Verbotonal Method. 


\section{Introducción}

\subsection{Acercamiento al concepto de ironía}

La ironía es un fenómeno complejo que ha sido abordado desde múltiples perspectivas a lo largo del tiempo. Desde la retórica tradicional, se ha explicado como un recurso para expresar lo contrario de lo que se dice (Marimón Llorca, 2009: 13). Esta definición ha sido superada en parte por la lingüística contemporánea, aunque su sencillez y su transparencia hacen que todavía pueda ser útil para determinados propósitos, como la enseñanza de lenguas extranjeras. Aun así, el desarrollo de la pragmática ha permitido analizar y describir exhaustivamente el acto irónico, que ya no se define necesariamente por la contradicción con el sentido literal del enunciado, sino por la inferencia de un contenido ilocutivo o intencional que se distancia del significado literal del enunciado, y cuya correcta interpretación depende en buena medida del contexto. Asimismo, teniendo en cuenta sus características perlocutivas o sus consecuencias, podemos afirmar que es una estrategia pragmática que puede producir daños en la imagen pública de los participantes (Padilla García, 2008: 279-281).

La comprensión y la producción de la ironía supone un verdadero reto para los aprendientes de Español como Lengua Extranjera (ELE) por varios motivos. Por un lado, la ironía tiene asociados diferentes valores sociopragmáticos en las diversas culturas (Roca Marín, 2009). Por ejemplo, en Inglaterra la ironía se considera un ejercicio de inteligencia e imaginación, mientras que para los alemanes es un acto hostil (Martí i Casanova, 1999). Por este motivo, se requiere una alta competencia pragmática en la lengua meta para saber utilizar la ironía convenientemente. Por otro lado, la interpretación del sentido irónico, como ya hemos mencionado, está fuertemente vinculada al contexto. Por contexto nos referimos no solo al entorno lingüístico y situacional, sino también al contexto sociocultural (Marimón Llorca, Padilla García, Ruiz Gurillo y Timofeeva, 2004: 235). Esto implica que, para interpretar adecuadamente los enunciados irónicos, en ocasiones es necesario que el hablante sea consciente de las creencias y actitudes que son propios de una cultura, lo que se traduce en la necesidad de una desarrollada competencia sociocultural.

Pese a todo, la ironía no es misión imposible para los aprendientes de ELE. Los enunciados irónicos no solo se detectan gracias al contexto, sino que, además, están marcados por algunos rasgos lingüísticos, fónicos y kinésicos que sirven de guía al oyente y aseguran la eficacia del acto comunicativo (Padilla García, 2008: 283). Estas marcas e indicadores de la ironía, que son particulares de cada lengua, afectan, al menos en español, a los ámbitos discursivo, sintáctico, morfológico, léxico, gráfico, fónico y kinésico (Ruiz Gurillo y Padilla García, 2009). Conocer estos indicadores puede ser clave para que los aprendientes de ELE sean capaces de comprender y producir eficazmente los enunciados irónicos. En nuestro trabajo, nos centraremos en la enseñanza de los marcadores e indicadores de estos dos últimos ámbitos, el fónico y el kinésico, aunque indirectamente, el aprendiente estará expuesto a enunciados irónicos marcados en otros niveles del lenguaje.

\subsection{Marcas prosódicas y kinésicas de la ironía}

Según el Diccionario de términos clave de ELE (1997), la prosodia se define como «el conjunto de fenómenos fónicos que abarcan más de un fonema o segmento», como, por 
ejemplo, la entonación, el acento, el ritmo, la velocidad de habla, el timbre, etc. La prosodia transmite múltiples informaciones al oyente, como la estructura de los enunciados, la gestión de la información en el discurso, el valor emotivo del mensaje o el origen geográfico del emisor. Además, puede informar sobre las actitudes del hablante y la intencionalidad del mensaje, es decir, sobre el significado pragmático del enunciado (Padilla García, 2011: 203). Por este motivo, no sorprende que la prosodia sea un aspecto clave a la hora de reconocer e interpretar los enunciados irónicos.

Aunque el estudio de Becerra Valderrama (2012) apunta a la falta de un patrón prosódico consistente que nos permita expresar y reconocer las distintas actitudes irónicas (como la crítica o la burla), sí que es posible encontrar frecuentemente rasgos asociados con el tono irónico de forma general. Podemos afirmar que los enunciados irónicos se caracterizan por una pronunciación enfática en uno o varios parámetros prosódicos, especialmente en las secciones del enunciado más relevantes para la transmisión del significado irónico. Más concretamente, siguiendo a Padilla García (2011), distinguimos marcas de la ironía en tres parámetros prosódicos: la duración, el tono y la intensidad.

1. El aumento de la duración del enunciado es el indicador prosódico más importante de la ironía y está presente en la gran mayoría de los enunciados irónicos. En ocasiones, puede afectar con mayor intensidad a algunas partes del enunciado, dando lugar a fenómenos como pausas, silabeo y alargamiento de sonidos vocálicos o consonánticos.

2. La entonación irónica se caracteriza por la subida de la frecuencia fundamental (a partir de ahora, F0), es decir, la emisión más aguda de la voz. Esta subida puede darse en tres momentos del enunciado: en el pico inicial de la curva entonativa, en la inflexión final de la curva entonativa o en una sílaba acústicamente destacada del enunciado, que recibe el nombre de foco acentual.

3. Los enunciados irónicos también suelen verse marcados por un aumento de la intensidad, aunque este factor es menos significativo que el resto de marcas e indicadores prosódicos.

En cuanto a la kinesia, según el Diccionario de términos de clave de ELE (1997), se define como «la disciplina que estudia los movimientos corporales conscientes e inconscientes que poseen un valor comunicativo». Los signos kinésicos, como los gestos faciales y los corporales, pueden tener un significado por sí mismos, o bien matizar el significado verbal y orientar su interpretación (Cestero Mancera, 2020). Cuando se trata de enunciados irónicos, las marcas kinésicas sirven precisamente para facilitar que el interlocutor reconozca la ironía, garantizando así la efectividad del mensaje. Siguiendo a Cestero Mancera (2009: 184), enumeramos a continuación algunas de las principales marcas kinésicas de la ironía.

1. Movimiento giratorio de los dedos índice y corazón. Puede ir acompañado de expresiones como ¿lo pillas?

2. Guiño. Guiñar un ojo, además de transmitir la ironicidad del enunciado, establece complicidad entre los interlocutores. 
3. Mirada. La mirada es el principal punto de contacto entre los interlocutores. Desviarla o mantenerla más de lo habitual puede comunicar la posición del hablante ante lo que dice, entre muchas otras cosas.

4. Sonrisa. Una sonrisa durante un enunciado puede revelar una particular intención comunicativa.

5. Encogimiento de hombros.

6. Arqueamiento de cejas.

7. Risa. La risa es un elemento paralingüístico que puede calificar todo el acto de enunciación.

\subsection{La enseñanza de la prosodia y la kinesia en el aula de ELE}

La enseñanza de la pronunciación, en general, y la enseñanza de la prosodia, en particular, han sido tradicionalmente desatendidas en la enseñanza de ELE, y aún hoy en muchas ocasiones siguen siendo olvidadas (Gutiérrez Menéndez, 2018: 277). Aún más precaria es la situación de la kinesia en el aula de ELE, pese a que recientemente se ha puesto de manifiesto la necesidad de enseñarla como parte del desarrollo de la competencia cultural (Fernández-Conde Rodríguez, 2017). Apenas existen hoy en día recursos y actividades al alcance de los profesores para trabajar los aspectos kinésicos del español.

Por este motivo, en este trabajo hemos decidido abordar la enseñanza de la ironía precisamente en el nivel prosódico y kinésico. Si bien la propuesta de actividades de Turcanu Vasiliu y Sempere Sempere (2019) supone un primer paso para la enseñanza de la entonación irónica, las autoras descartan el resto de parámetros prosódicos, como la duración o la intensidad, pese a que precisamente el aumento de la duración es la marca de la ironía más relevante en el nivel prosódico (García Padilla, 2011: 224). Por otro lado, las autoras (2019: 325) consideran conveniente la creación de actividades que combinen la enseñanza de la entonación irónica con los elementos kinésicos que acompañan la ironía. A nuestro parecer, se trata de algo necesario, ya que no existen hasta el momento recursos ni actividades para trabajar las marcas kinésicas de la ironía en el aula de ELE.

Una de las propuestas de Hidalgo Navarro y Cabedo Nebot (2012) para la enseñanza de la entonación es seguir la metodología utilizada en el Método Verbo-Tonal (MVT), en el que nos hemos basado para llevar a cabo nuestra unidad didáctica. Este método, creado a mediados del siglo pasado por Petar Guberina (1961), puso de relieve la importancia de la prosodia y la kinesia en el conjunto de la enseñanza de la pronunciación, y, a día de hoy, sigue siendo el marco más adecuado para trabajar la kinesia y la prosodia en el aula de lenguas extranjeras (Padilla García, 2015: 75-76). Según el MVT, la enseñanza de la prosodia y de la kinesia debe ser prioritaria y temprana, no solo por la importancia que tienen estos niveles por sí mismos, sino porque además facilitan el aprendizaje de la pronunciación en el nivel fonemático. Complementariamente a los principios del MVT, nuestra propuesta didáctica incluye actividades de «percepción», «reflexión»y «producción», en ese orden, lo que responde a la organización que propone el enfoque fono-cognitivo (Padilla García, 2015: 77). 


\section{Unidad didáctica}

\subsection{Ficha técnica}

\begin{tabular}{|c|c|}
\hline NIVEL & $\mathrm{C} 1$ \\
\hline OBJETIVOS & $\begin{array}{l}\text { - Activar los conocimientos previos sobre la ironía } \\
\text { teniendo en cuenta el factor intercultural. } \\
\text { - Diferenciar los enunciados irónicos y los no } \\
\text { marcados. } \\
\text { - } \quad \begin{array}{l}\text { Reconocer las marcas prosódicas y kinésicas de la } \\
\text { ironía. }\end{array} \\
\text { - Producir enunciados irónicos adecuados, poniendo en } \\
\text { práctica las marcas kinésicas y prosódicas de la } \\
\text { ironía. }\end{array}$ \\
\hline DESTREZAS & Comprensión oral, expresión oral e interacción \\
\hline CONTENIDOS & $\begin{array}{l}\text { - Marcas prosódicas de la ironía: duración, entonación } \\
\text { irónica e intensidad. } \\
\text { - Marcas kinésicas de la ironía: gestos faciales y } \\
\text { corporales. } \\
\text { - Contraste entre los actos irónicos y los no irónicos. }\end{array}$ \\
\hline DESTINATARIOS & Jóvenes y adultos \\
\hline DINÁMICA & Individual, parejas, grupo \\
\hline DURACIÓN & 3 sesiones de 30 minutos \\
\hline MATERIALES & $\begin{array}{l}\text { Ordenador, proyector, altavoces, PowerPoint, vídeos y } \\
\text { materiales en casa complementarios }\end{array}$ \\
\hline $\begin{array}{c}\text { OBSERVACIONES } \\
\text { PARA EL PROFESOR }\end{array}$ & $\begin{array}{l}\text { - El profesor no debe abusar de presentarse a sí mismo } \\
\text { como modelo de pronunciación. } \\
\text { - Se recomienda crear un ambiente de confianza, por } \\
\text { ejemplo, a través de un entorno distendido o } \\
\text { informal. }\end{array}$ \\
\hline
\end{tabular}

Tabla 1. Ficha técnica de la unidad didáctica

\subsection{Destinatarios}

Teniendo en cuenta el Plan Curricular del Instituto Cervantes, consideramos que el nivel en el que se debería emplear esta unidad didáctica es el $\mathrm{C} 1$, puesto que la ironía aparece mencionada en los niveles $\mathrm{C} 1$ y $\mathrm{C} 2$ del Plan Curricular. También creemos que los destinatarios más apropiados para llevar a cabo el desarrollo de esta clase serán los aprendientes de español jóvenes y adultos. Pensamos que estos estudiantes son los más 
adecuados para participar en esta sesión al tener en cuenta el contenido que utilizaremos, pues se trata de material audiovisual perteneciente a una serie española, y el contenido que incluye es el más conveniente para este rango de edad. Por otro lado, no pensamos que estas actividades estén restringidas a estudiantes de algún origen específico ni tampoco hemos considerado que su uso esté limitado a una clase de español con condiciones determinadas (en el extranjero, en inmersión, etc.) ya que creemos que puede beneficiar a estudiantes de diferentes países de procedencia. Es por eso por lo que hemos incluido también preguntas al principio de la clase (que desarrollaremos más adelante [véase 3.2.]) sobre las diferencias entre el uso de la ironía en los posibles distintos países de procedencia. De esta forma se tendrá en cuenta el factor intercultural en el aula. Por último, al ser una actividad con un rango de uso amplio, nos gustaría dejar libertad al profesor para que sea el encargado de adaptarla a su clase de la manera que le convenga.

\subsection{Sobre los materiales visuales y audiovisuales}

Para la realización de esta unidad didáctica, hemos utilizado cuatro tipos diferentes de materiales visuales y audiovisuales: vídeos de YouTube, grabaciones creadas especialmente para esta unidad didáctica, imágenes de curvas entonativas obtenidas gracias al programa PRAAT y fragmentos de audio y vídeo de la serie española Aquí no hay quién viva. Estos materiales podrían presentarse de forma secuenciada a través de una presentación en PowerPoint o Google Presentations. Para compartir todos los materiales, que describimos a continuación, hemos creado una carpeta en Google Drive 1 de libre acceso, donde se ponen a disposición general. De esta forma, pretendemos facilitar su uso a aquellas personas interesadas en la utilización o adaptación de esta propuesta didáctica.

El primer elemento audiovisual que utilizamos es un vídeo obtenido de la plataforma digital YouTube. Este vídeo documenta el salto de un motorista en un torneo de motocross freestyle y lo hemos incluido con el propósito de utilizarlo como metáfora para explicar la parte teórica de nuestra unidad didáctica. Tanto el salto como los movimientos que el motorista realiza antes, durante y después del mismo, nos servirán para introducir de forma visual las marcas prosódicas y kinésicas de la ironía que detallaremos más adelante en la tabla 2.

En segundo lugar, mostraremos a los alumnos y alumnas cuatro grabaciones creadas para el desarrollo de esta unidad. Estas grabaciones se llevaron a cabo de forma controlada, con un sujeto que no conocía de forma explícita las marcas prosódicas ni kinésicas de la ironía. Sin embargo, le pedimos al sujeto que fuera enfático con la voz y los gestos para marcar los actos irónicos y poder presentarlos de forma más clara. En estas grabaciones se presentan dos enunciados distintos (Gracias por ser tan comprensiva y Se nota que has trabajado mucho) pronunciados cada uno dos veces, una vez de forma irónica y otra vez de forma no irónica. Esto permite contrastar de forma explícita el modelo irónico y el modelo declarativo no marcado. De esta manera, pretendemos que los alumnos y las alumnas focalicen su atención en las diferencias prosódicas y kinésicas de cada pareja de grabaciones, facilitando el reconocimiento de las marcas irónicas y kinésicas de la ironía.

\footnotetext{
${ }^{1}$ https://drive.google.com/drive/folders/1d906mLoGPGYU1b5No2yutv9_fQUCozGf?usp=sharing
} 
En tercer lugar, hemos utilizado imágenes de las curvas entonativas de estas grabaciones que han sido creadas con el programa informático PRAAT. Estas imágenes ayudarán a los estudiantes a apreciar de forma más visual las marcas entonativas de la ironía. Para que este proceso sea apreciado fácilmente y poder marcar el primer pico o el foco acentual, hemos añadido dibujos de motoristas circulando por las curvas entonativas de los enunciados no irónicos y dibujos de motoristas realizando acrobacias en el aire para marcar los actos irónicos. Las acrobacias representadas en los dibujos nos servirán también como metáfora para explicar los rasgos kinésicos que acompañan a la parte prosódica (la curva entonativa ya representada y mencionada).

Por último, como ejemplo para que los estudiantes identifiquen y demuestren que han asimilado la teoría explicada, hemos escogido varios fragmentos audiovisuales de la serie española Aquí no hay quien viva (ANHQV). En estos fragmentos se presentan ejemplos de actos irónicos y no irónicos que los alumnos y las alumnas se encargarán de clasificar en la actividad de percepción. La elección de estos fragmentos no ha sido de forma arbitraria, sino que hemos elegido una serie de ficción cómica puesto que, por un lado, se trata de un tipo de discurso que emula la oralidad espontánea y, por otro lado, se caracteriza por una pronunciación clara y una prosodia y kinesia marcadas (Martínez Hernández, 2019: 79). Los fragmentos seleccionados están disponibles en la carpeta de Google Drive para quienes deseen aplicar esta unidad didáctica en sus clases.

\subsection{Materiales complementarios}

Los materiales necesarios para la realización en clase de esta unidad didáctica son los siguientes: un ordenador que esté conectado a un proyector (o una pizarra digital), altavoces y una presentación de Google Presentaciones o PowerPoint para utilizar como guion de referencia. Además, para poder llevar a cabo los ejercicios de experimentación de forma autónoma (que realizarán en grupo fuera de clase) los estudiantes deben disponer de un móvil con cámara, grabadora o algún aparato electrónico que les permita grabar material audiovisual y audio.

\subsection{Sobre PRAAT}

Como ya hemos mencionado anteriormente, utilizamos el programa PRAAT ${ }^{2}$ (Boersma y Weenink, 2020) para representar las gráficas de las curvas entonativas de las oraciones irónicas y de los modelos declarativos no marcados. Este programa informático de libre acceso, creado por Paul Boersma y David Weenink en 1992, nos permite estudiar e investigar particularidades prosódicas como las que hemos puesto de manifiesto en nuestra unidad didáctica. Las gráficas que hemos incluido en esta unidad facilitan el aprendizaje de la entonación irónica a los aprendientes que no están familiarizados con conceptos referentes con la entonación. Las curvas entonativas que presentamos han sido estilizadas mediante la opción «PitchTier», que ofrece el propio programa informático.

Consideramos que este programa es muy intuitivo y sencillo, pero aconsejamos que los docentes que estén interesados en su uso consulten cualquiera de los tutoriales disponibles en internet de forma gratuita, así como en páginas webs que nos han servido

\footnotetext{
${ }^{2}$ https://www.fon.hum.uva.nl/praat/
} 
de guía ${ }^{3}$. Las opciones que este programa ofrece son numerosas, por lo que estos tutoriales y páginas son muy recomendables para sacarle el máximo partido.

\section{Procedimiento}

\section{1. Actividad de presentación del modelo}

Objetivos:

En la primera actividad queremos presentar un modelo que sirva para que el alumno sepa lo que va a aprender y lo que vamos a exigir que realice. Por lo tanto, como el objetivo de nuestra unidad didáctica es enseñar algunos rasgos prosódicos y kinésicos característicos de la ironía, presentaremos un modelo irónico que esté contextualizado. Además, en esta actividad inicial, queremos enseñar el modelo de manera que capte la atención de los estudiantes a través de la sorpresa y el impacto.

Procedimiento:

El profesor, con la ayuda de un colaborador (puede tratarse de algún alumno o pedirle a algún otro docente que le asista), creará un roleplay en el que mostrará un ejemplo de ironía en un contexto real. Este roleplay puede plantearse de distintas maneras, como pedirle al alumno colaborador que llegue tarde a clase para poder comentar lo puntual que es de forma irónica o que el profesor que le asista interrumpa sin llamar a la puerta del aula y darle las gracias por ser tan oportuno; o cualquier situación en la que se utilice un enunciado irónico verosímil para presentar de forma clara y contextualizada el modelo irónico.

\subsection{Actividad de introducción}

Objetivos:

Con esta actividad se pretende que la clase empiece de una manera distendida explicando la ironía mediante la creación de un pequeño debate, que, además, busca el desarrollo de las destrezas orales. Asimismo, queremos que el alumnado active los conocimientos generales de la ironía tanto en su lengua materna como en la lengua meta. Se busca contrastar los diferentes aspectos y las diferencias de la ironía en el país de origen de los estudiantes con respecto a la cultura meta. Por último, también, se pone el foco en el factor intercultural.

Procedimiento:

Para el desarrollo de esta actividad queremos generar un pequeño debate y para ello se pueden utilizar las siguientes preguntas:

1. ¿Te consideras una persona irónica?

2. ¿Es la gente irónica en tu país?

3. ¿Cómo expresas la ironía en tu lengua materna? Es decir, ¿qué haces cuando eres irónico?

\footnotetext{
${ }^{3}$ http://liceu.uab.es/ joaquim/phonetics/fon_Praat/Praat.html
} 
4. ¿Crees que tú expresas más la ironía con el tono de voz, con gestos, con palabras...?

5. ¿Consideras que los españoles son muy irónicos o poco irónicos?

Con estas preguntas se pretende romper el hielo y buscar la comunicación, pero también que los aprendientes compartan sus opiniones personales y manifiesten las particularidades de su cultura. Esta actividad persigue igualmente la reflexión y la toma de conciencia metalingüística de lo que supone la ironía. Se comienza preguntando sobre el propio aprendiente y su cultura, de forma que los alumnos y alumnas puedan llevar a cabo una reflexión intercultural. Para finalizar, las preguntas van encaminadas hacia una reflexión sobre la ironía en la cultura meta.

\subsection{Actividad de reflexión y contraste}

Objetivos:

Con esta actividad el alumno pasará a tomar conciencia del fundamento teórico que compone esta unidad didáctica, es decir, las marcas prosódicas y kinésicas de la ironía. Por este motivo, esta actividad es la más densa de la secuencia y requiere un grado de concentración más elevado que las demás. Para facilitar este objetivo, por un lado, utilizaremos elementos visuales y metafóricos, y por otro, se llevará a cabo un contraste entre el modelo irónico y el modelo no marcado.

Procedimiento:

En primer lugar, se mostrará un vídeo de un deportista practicando motocross freestyle (véase 2.3.). A continuación, se tratará de obtener, por parte de los alumnos y las alumnas, algunos parámetros por los que la actuación del motorista se podría juzgar o valorar. A partir de dichos parámetros, se establecerán una serie de correspondencias metafóricas entre el salto del motorista y las marcas prosódicas y kinésicas presentes en un acto irónico. De este modo, se pretende facilitar la comprensión y la memorización de los rasgos de la prosodia y la kinesia de la ironía, evitando un metalenguaje excesivo. Las correspondencias se encuentran en la siguiente tabla.

\begin{tabular}{|c|c|}
\hline $\begin{array}{c}\text { Parámetros que deben tenerse en cuenta } \\
\text { de una actuación de motocross freestyle }\end{array}$ & $\begin{array}{c}\text { Marcas prosódicas y kinésicas de un acto } \\
\text { irónico }\end{array}$ \\
\hline $\begin{array}{c}\text { Acrobacia o figura que el deportista realiza } \\
\text { en el aire. }\end{array}$ & $\begin{array}{c}\text { Marcas kinésicas: gestos faciales, } \\
\text { movimientos de manos, brazos, tronco... }\end{array}$ \\
\hline Altura que alcanza el motorista. & $\begin{array}{c}\text { Subida de la F0 (en el primer pico, inflexión } \\
\text { final y foco acentual). }\end{array}$ \\
\hline $\begin{array}{c}\text { Tiempo que tarda el deportista en realizar su } \\
\text { actuación. }\end{array}$ & $\begin{array}{c}\text { Aumento de la duración de emisión y } \\
\text { fenómenos derivados. }\end{array}$ \\
\hline $\begin{array}{c}\text { Gritos, aplausos o silbidos que el motorista } \\
\text { es capaz de despertar en el público. }\end{array}$ & Aumento de la intensidad. \\
\hline
\end{tabular}

Tabla 2. Correspondencias metafóricas para explicar las marcas de un acto irónico 
Una vez se presentan las marcas kinésicas y prosódicas de la ironía a través de la metáfora, se pasa al ejercicio de contraste entre el modelo irónico y el modelo no marcado. Para ello, utilizaremos grabaciones audiovisuales, en las que se pronuncian los enunciados Se nota que has trabajado mucho y Gracias por ser tan comprensiva tanto de forma irónica como de forma no irónica (véase 2.3.). En primer lugar, se mostrarán las grabaciones con imagen y sonido, de modo que los aprendientes detecten que solo uno de los enunciados es pronunciado de forma irónica. A continuación, se mostrarán las imágenes sin sonido, y se pedirá a los estudiantes que digan qué rasgos kinésicos les llaman la atención en el contraste entre el acto irónico y su correlato no marcado. De este modo, se pretende que la atención del estudiante se centre en los elementos kinésicos y se haga un análisis detallado de dichas marcas de la ironía presentes en las grabaciones. En la siguiente tabla, se muestran las marcas kinésicas que se pueden encontrar en las grabaciones.

\begin{tabular}{|c|c|}
\hline Se nota que has trabajado mucho & Gracias por ser tan comprensiva \\
\hline $\begin{array}{l}\text { - Cejas. El sujeto levanta las cejas y } \\
\text { frunce el ceño. } \\
\text { - Mirada. El sujeto desvía la mirada } \\
\text { de su interlocutor, hacia la izquierda } \\
\text { y hacia la derecha. } \\
\text { - Sonrisa. El sujeto estira los labios, } \\
\text { esbozando una sonrisa forzada. Al } \\
\text { final, redondea los labios y los } \\
\text { aprieta. } \\
\text { - Brazos y manos. El sujeto agarra su } \\
\text { chaqueta y balancea ligeramente sus } \\
\text { brazos, abriéndolos y cerrándolos. }\end{array}$ & $\begin{array}{l}\text { - Cabeza. El sujeto ladea la cabeza } \\
\text { hacia la izquierda, y después, } \\
\text { ligeramente hacia la derecha. } \\
\text { - Sonrisa. Al acabar de producir el } \\
\text { enunciado, el sujeto sonríe. } \\
\text { - Brazos y manos. El sujeto abre sus } \\
\text { brazos y sus manos delante de él. A } \\
\text { continuación, los vuelve a cerrar. } \\
\text { - Cejas. El sujeto levanta las cejas y } \\
\text { frunce el ceño. }\end{array}$ \\
\hline
\end{tabular}

Tabla 3. Principales marcas kinésicas de la ironía en las grabaciones

Una vez analizadas las marcas kinésicas, se muestran las curvas melódicas de los enunciados (véase 2.3), estilizadas mediante el programa PRAAT, y a la vez, se reproduce el sonido de las grabaciones sin imagen. De esta manera, toda la atención del estudiante se focalizará en identificar las marcas prosódicas de la ironía, a través del contraste con los enunciados irónicos. Gracias a las imágenes de las curvas entonativas, el alumno puede visualizar la subida de la F0 en el pico inicial, la inflexión final o el foco acentual, y al mismo tiempo puede percatarse del aumento de la duración del enunciado en general, y de algunas sílabas en particular. 


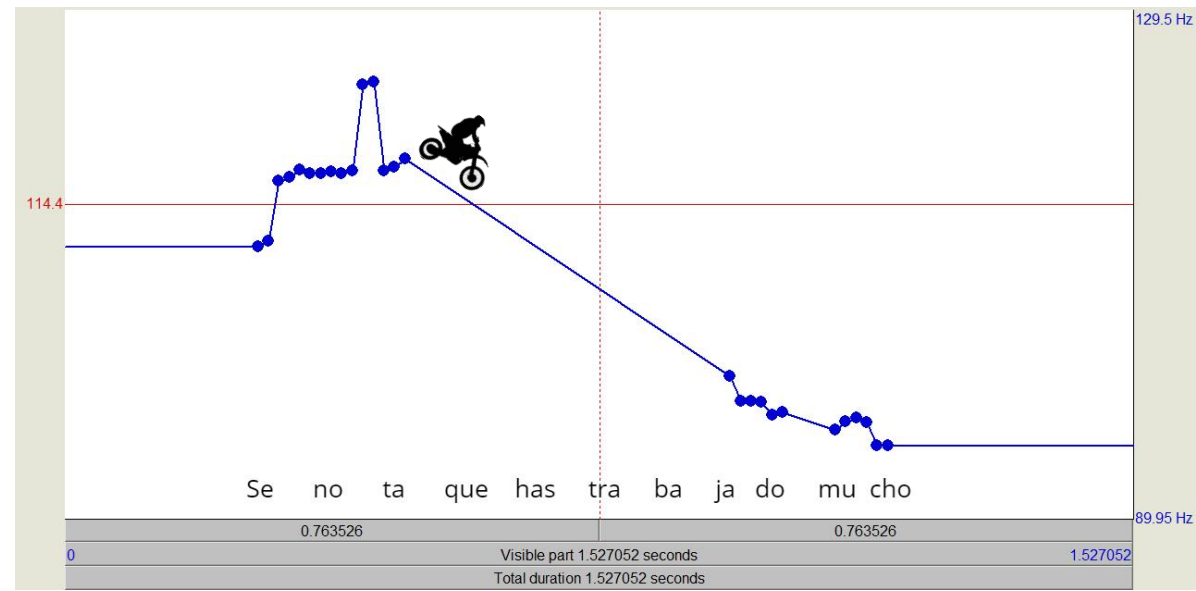

Figura 1. Curva entonativa de Se nota que has trabajado mucho (no irónico)

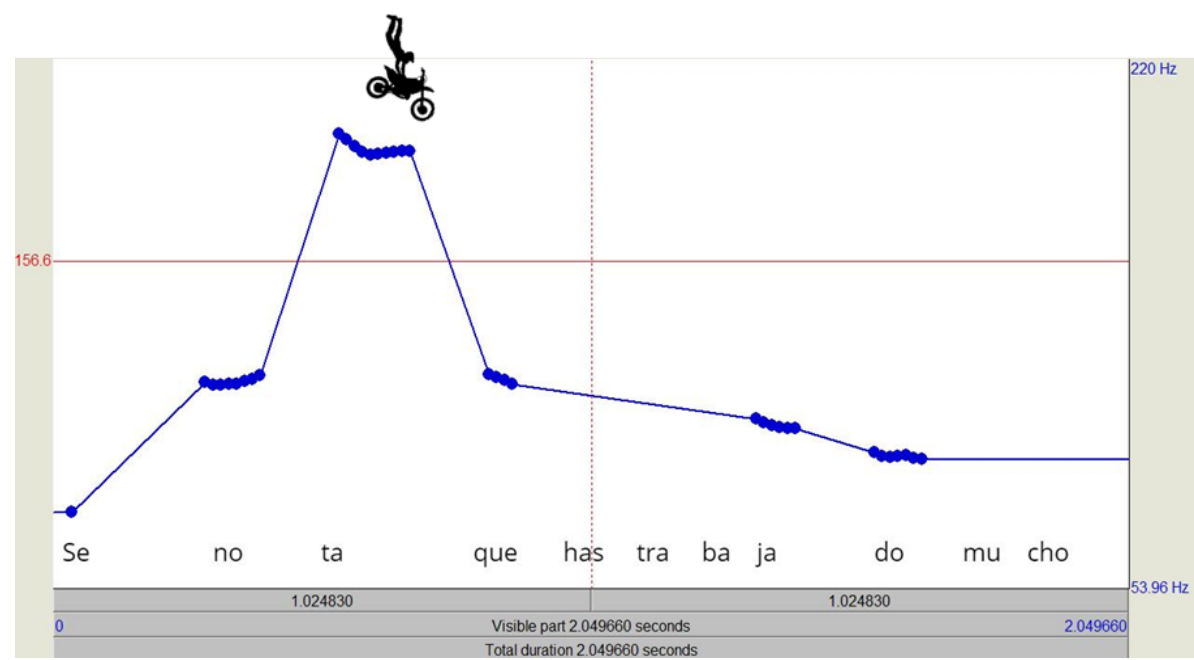

Figura 2. Curva entonativa de Se nota que has trabajado mucho (irónico)

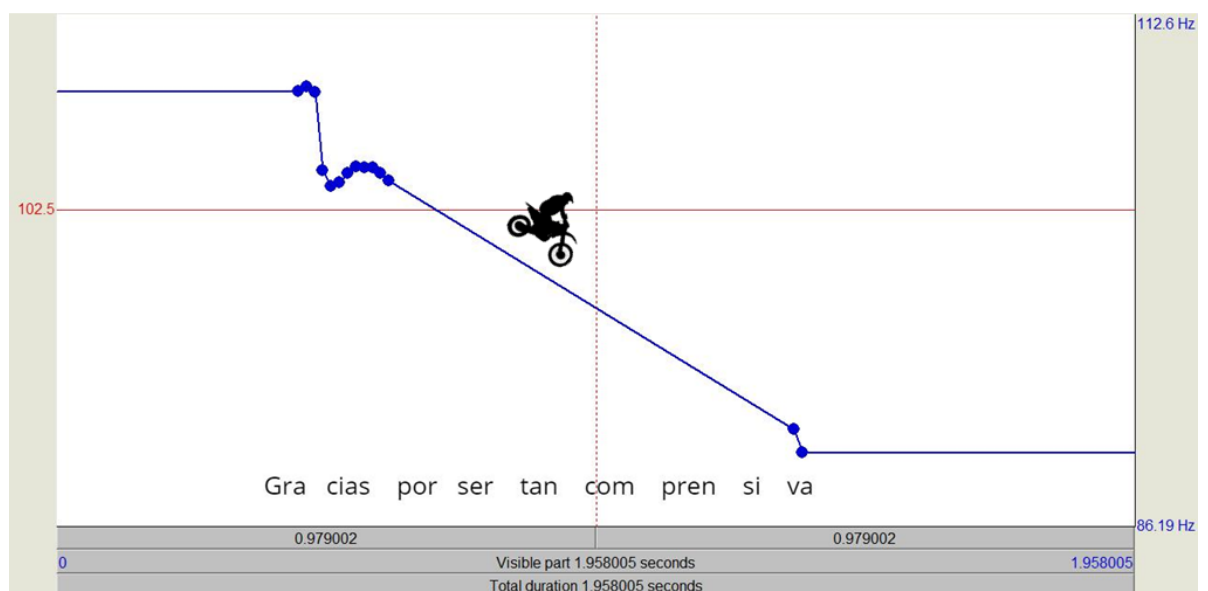

Figura 3. Curva entonativa de Gracias por ser tan comprensiva (no irónico) 


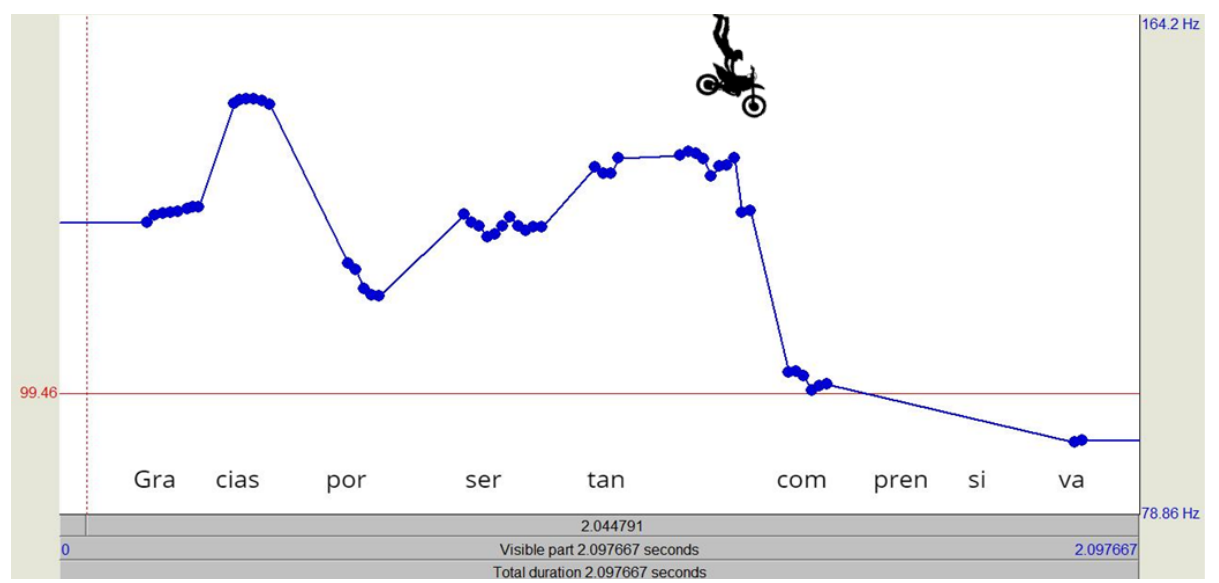

Figura 4. Curva entonativa de Gracias por ser tan comprensiva (irónico)

En la siguiente tabla se muestran las marcas prosódicas que se aprecian en los enunciados irónicos en contraste con los enunciados no marcados:

\begin{tabular}{|c|c|}
\hline Se nota que has trabajado mucho & Gracias por ser tan comprensiva \\
\hline $\begin{array}{l}\text { - Duración. La duración del enunciado } \\
\text { aumenta de 1,5 a } 2 \text { segundos, } \\
\text { especialmente en la tercera sílaba, "ta", } \\
\text { que es el foco acentual. } \\
\text { - Entonación. Se aprecia un aumento } \\
\text { significativo de la F0 en la tercera } \\
\text { sílaba, "ta", que constituye el primer } \\
\text { pico y que, en este caso, coincide con el } \\
\text { foco acentual. }\end{array}$ & $\begin{array}{l}\text { - Duración. La duración del enunciado } \\
\text { aumenta de forma generalizada, y } \\
\text { especialmente en la sílaba "tan", el } \\
\text { foco acentual, donde notamos un } \\
\text { particular alargamiento del sonido } \\
\text { nasal. } \\
\text { - Entonación. Sube la F0 del primer } \\
\text { pico, que corresponde a la segunda } \\
\text { sílaba, y del foco acentual, que } \\
\text { corresponde a la sílaba "tan". } \\
\text { - Intensidad. Se aprecia un aumento de } \\
\text { la intensidad en el foco acentual". }\end{array}$ \\
\hline
\end{tabular}

Tabla 5. Principales marcas prosódicas de la ironía en las grabaciones

\subsection{Actividad de percepción consciente}

Objetivos:

A partir de fragmentos de la serie de televisión Aqui no hay quien viva (ANHQV) los alumnos y las alumnas aprenden a identificar los enunciados irónicos y a diferenciarlos de los no marcados. Los aprendientes se apoyarán en las marcas prosódicas y kinésicas que se han presentado previamente.

Procedimiento:

Para empezar, se informará a los estudiantes de que van a escuchar y a ver fragmentos de una serie española y que algunos contendrán enunciados irónicos, mientras que otros, actos no marcados. Se reproducirán uno a uno los fragmentos, y los aprendientes

4 Aunque no hemos mostrado el parámetro intensidad en las imágenes de PRAAT, en este caso, el aumento de la intensidad en la sílaba "tan" se aprecia con tanta claridad en la grabación que creemos que los alumnos no tendrán problemas para identificarlo. 
tendrán que identificar cuáles muestran actos irónicos y cuáles no. Tras una segunda reproducción, en el caso de los fragmentos irónicos, los alumnos y las alumnas han de identificar qué marcas prosódicas y kinésicas les han ayudado a reconocer los enunciados irónicos. A continuación, en la siguiente tabla, a modo de ejemplo, se presentan las principales marcas prosódicas y kinésicas de ironía que aparecen en dos de los vídeos elegidos.

\begin{tabular}{|c|c|}
\hline Ay, muchas gracias [...] & Sí hombre, hasta el tercero [...] \\
\hline 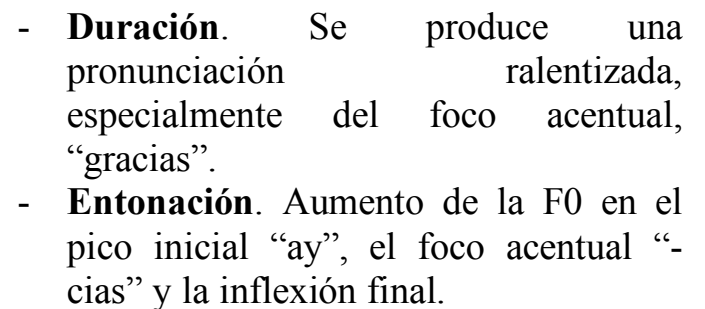 & $\begin{array}{l}\text { - Duración. Ralentización en “muchas } \\
\text { gracias, ¿eh?”. } \\
\text { - Intensidad. Aumento de la intensidad } \\
\text { en “muchas gracias, ¿eh?”. } \\
\text { - Kinesia. Gesto con la mano, dedo } \\
\text { índice levantado (hombre). Alzamiento } \\
\text { de cejas (mujer). }\end{array}$ \\
\hline
\end{tabular}

Tabla 5. Principales marcas prosódicas y kinésicas de ironía en los fragmentos de ANHQV

\subsection{Actividad de producción consciente}

Objetivos:

Con esta actividad se pretende que, tras lo visto a lo largo de los ejercicios anteriores, los aprendientes puedan poner en práctica de forma clara y manifiesta lo aprendido. Los aprendientes tendrán que utilizar de forma consciente las marcas prosódicas y kinésicas que caracterizan a la ironía, así como lo relativo a los enunciados no marcados. Se busca que la producción consciente pase a ser inconsciente en el menor tiempo posible. Además, se introduce un elemento lúdico con el que se busca lograr la participación y la motivación de los alumnos y las alumnas.

Procedimiento:

Para la realización de esta actividad se dividirá la clase en parejas. Se necesitarán dos bolsas con papeles, una de ellas contendrá el nombre de algún miembro de la clase y en la otra se encontrarán adjetivos que describan la personalidad como, por ejemplo, impuntual (no se incluirán adjetivos calificativos como guapo o feo). Cada pareja que se ha formado anteriormente extraerá un papel de las bolsas y, tras esto, crearán una oración con el nombre del estudiante y el adjetivo que han sacado. Por un lado, tendrán que crear un enunciado irónico teniendo en cuenta los rasgos prosódicos y kinésicos de la ironía que han visto a lo largo de toda la sesión y, por otro lado, tendrán que hacer lo mismo formando una oración no irónica.

A continuación, las parejas presentarán el trabajo. Un miembro de la pareja tendrá que presentar el modelo irónico, mientras que el otro interpretará el no irónico. El profesor preguntará al resto de la clase qué miembro de la pareja está presentando el modelo irónico y quién no. Los estudiantes tendrán que votar según lo que piensen y estos votos se irán apuntando. Una vez hecho con todas las parejas, se revelarán las respuestas correctas y se premiará a aquel que haya obtenido más respuestas correctas. Con este sistema de puntos se busca la motivación de los estudiantes. 


\subsection{Actividad de experimentación: rasgos prosódicos}

Objetivos:

En este primer ejercicio de experimentación, los aprendientes, partiendo de lo visto, tendrán que crear enunciados nuevos para los fragmentos de ANHQV. En este ejercicio se pretende que los estudiantes practiquen y acaben de fijar los conocimientos relativos a los rasgos prosódicos de los enunciados irónicos y no irónicos. Además, también tiene como objetivo dar más autonomía al estudiante.

Procedimiento:

Para la realización de este ejercicio, los aprendientes tendrán que elegir alguno de los fragmentos de ANHQV con los que se ha trabajo en la actividad de percepción consciente. Por tanto, la clase se dividirá según el número de personajes que aparezcan en el vídeo. Sobre las imágenes del vídeo elegido, los aprendientes crearán y grabarán un diálogo nuevo en el que tendrán que usar tanto enunciados irónicos como no irónicos. Este ejercicio se preparará en casa y se presentará en clase en la siguiente sesión.

\subsection{Actividad de experimentación: rasgos kinésicos}

Objetivos:

En este segundo ejercicio de experimentación se pretende que los aprendientes fijen las marcas kinésicas de los enunciados irónicos con lo que se ha visto a lo largo de toda la secuencia de actividades. Como en el ejercicio anterior, se trata de una actividad de producción libre por lo que se busca que los alumnos y las alumnas obtengan más autonomía.

Procedimiento:

Para esta actividad la clase se dividirá en grupos de dos o tres personas. Los estudiantes tendrán que crear una historia en la que se intercalen enunciados irónicos y no irónicos para después representarla. En este caso, tendrán que eliminar el sonido y solo se ayudarán de las marcas kinésicas para identificar el tipo de enunciado que están presentando. Esta actividad se preparará en casa y, después, tendrán que presentar el trabajo en clase para que el resto de estudiantes trate de adivinar lo que están diciendo a través de la kinesia.

\section{Conclusión y futuras líneas de desarrollo}

Gracias a los estudios previos sobre la ironía en el aula de ELE, hemos podido comprobar que la enseñanza de la misma era posible. Estos estudios se centran en diferentes formas de abordar la ironía en las clases de ELE y, para nuestra propuesta, nos hemos basado en las perspectivas referentes a la prosodia, así como a los rasgos kinésicos propios de este fenómeno. Además, los materiales creados para la enseñanza de las características prosódicas de la ironía nos sirvieron como punto de partida para nuestra propuesta de actividades, a la que añadimos también las características kinésicas, ausentes en trabajos anteriores. A pesar de encontrar varios estudios sobre la kinesia de la ironía, no hallamos actividades y propuestas de enseñanza sobre este 
aspecto. También nos guiamos por los parámetros del método verbo-tonal y adoptamos un enfoque fonocognitivo, que facilitan la enseñanza de dichos rasgos de la ironía, al igual que el programa informático PRAAT. En este trabajo, hemos presentado una secuencia de actividades posibles para enseñar la ironía a estudiantes de ELE, focalizando la atención en las marcas prosódicas y kinésicas de la ironía. Las actividades propuestas ofrecen a los aprendientes las herramientas necesarias tanto para reconocer como para producir enunciados irónicos. Además, tras la realización de este trabajo y tras la experiencia enriquecedora de presentar nuestra propuesta en el XVI Foro de Profesores de ELE, hemos detectado algunas líneas de trabajo que convendría desarrollar en el futuro, que presentamos a continuación.

En primer lugar, en cuanto a los materiales, sería beneficioso para el estudiante contar con las imágenes del PRAAT en movimiento, es decir, imágenes dinámicas en las que el motorista se deslice por la curva entonativa mientras que la frase se reproduce. Además, en el caso del ejemplo del enunciado irónico, sería conveniente que el motorista realizara las acrobacias correspondientes en el pico inicial o en el foco acentual. De esta forma, consideramos que el estudiante sería capaz de interpretar y visualizar con mayor facilidad los rasgos prosódicos de la ironía.

En segundo lugar, consideramos que esta unidad didáctica podría ser mejorada si, además de integrar las marcas prosódicas y kinésicas que hemos trabajado, se integrasen las marcas de la ironía en otros niveles del lenguaje, como la morfología, la sintaxis, el léxico, la fraseología, etc. De esta forma, conformaríamos una unidad didáctica completa que podría desarrollarse a lo largo de varias sesiones. Para estudiar un aspecto tan complejo como puede resultar la ironía, es recomendable tener en cuenta todas sus marcas e indicadores.

Por último, durante la elaboración de este trabajo, hemos detectado una falta de estudios en este campo, especialmente en lo que se refiere a la enseñanza de la kinesia. Por tanto, tras esta investigación, consideramos importante llevar a cabo un estudio más profundo de estas marcas kinésicas. Creemos que es de vital importancia la enseñanza de la kinesia, puesto que cumple una función clave en la comunicación, ya que la pronunciación de sonidos va acompañada por movimientos que facilitan su comprensión.

\section{Bibliografía}

BECERRA VALDERRAMA, M. ${ }^{a}$ I. (2012). «Rasgos prosódicos en la producción de dos formas de la ironía», Lingüística, 28, pp. 191-205.

Boersma, P. y Weenink, D. (2020). Praat: doing phonetics by computer (Versión 6.1.16) [Programa informático]. Recuperado el 06/06/2020 de http://www.praat.org/

Cestero Mancera, A. M. ${ }^{a}$ (2009). «Marcas paralingüísticas y kinésicas de la ironía». En L. Ruiz Gurillo y Xose A. Padilla García (eds.), Dime cómo ironizas y te diré quién eres. Una aproximación pragmática a la ironía (pp. 167-190). Frankfurt am Main: Peter Lang.

Cestero Mancera, A. M. a (2020). «Comunicación no verbal». En M. E. Placencia y Xose A. Padilla García (eds.), Guía práctica de pragmática del español (pp. 206-216). Londres / Nueva York: Routledge. 
FERNÁNDEZ-CONDE RODRÍGUEZ, M. (2017). «La enseñanza de la comunicación no verbal en el aula: necesidad y propuestas de explotación». V Jornadas de Didáctica del Español como Lengua Extranjera, 5, pp. 56-67.

GUBERINA, P. (1961). «La méthode audio-visualle structuro-globale et ses implications dans l'enseignement de la phonétique». Studia Romanica et Anglica Zagrabiensia, 11, pp. $12-40$.

GutiÉRrez MENÉndEZ, D. (2018). «La prosodia en la clase de ELE. Aplicaciones prácticas en el aula», Monográficos SINOELE, 17, pp. 276-285.

Hidalgo Navarro, A. y CABEdo Nebot, A. (2012). La enseñanza de la entonación en el aula de E/LE. Madrid: Arco/Libros.

InSTITUTO CERVANTES (2006). El plan curricular del Instituto Cervantes: niveles de referencia para el español [en línea]. Recuperado de: https://cvc.cervantes.es/ensenanza/biblioteca_ele/plan_curricular/

Marimón llorca, C., Padilla García, X. A., Ruiz-Gurillo, L. y Timofeeva, L. (2004). «El proyecto GRIALE para la ironía en español: conceptos previos». E.L.U.A: Estudios de lingüistica. Universidad de Alicante, 18, pp. 231-242.

MARTí I CASANOVA, J. C. (1999). «La traducció cultural: el concepte d'ironia en francés, anglés, espanyol i català». En Martos Sánchez (ed.), La traducció del discurs (pp. 77-93). Alicante: Servicio de Publicaciones de la Universidad de Alicante.

MARTín Peris, E. (dir.) (2008). Diccionario de términos clave de ELE [en línea]. Recuperado de: https://cvc.cervantes.es/ensenanza/biblioteca_ele/diccio_ele/indice.htm

MARTÍNEZ HERNÁNDEZ, D. (2019). La expresión de la ironía en la conversación: estudio fonopragmático en un corpus de habla espontánea (Tesis doctoral). Universitat de València.

PADilla GARCíA, X. A. (2008). «Claves para abordar la ironía en programas de ELE. De la competencia comunicativa a la competencia intercultural». Verba, 35, pp. 275303.

PADILlA GARCíA, X. A. (2011). «Existen rasgos prosódicos objetivos en los enunciados irónicos?». Oralia: Análisis del discurso oral, 4, pp. 203-226.

Padilla García, X. A. (2015). La pronunciación del español: Fonética y enseñanza de lenguas. Alicante: Servicio de Publicaciones de la Universidad de Alicante.

Roca Marín, S. (2009). «Ironía e interculturalidad». En L. Ruiz Gurillo. y X. A. Padilla García (eds.), Dime cómo ironizas y te diré quién eres. Una aproximación pragmática a la ironía (pp. 457-477). Frankfurt am Main: Peter Lang.

Ruiz Gurillo, L. y Padilla García, X. A. (eds.) (2009). Dime cómo ironizas y te diré quién eres. Una aproximación pragmática a la ironía. Frankfurt am Main: Peter Lang.

Turcanu VAsiliu, C. y SEMPERE SEMPERE, I. (2019). «Claves para trabajar la entonación irónica con alumnos de ELE», Foro de profesores de E/LE, 15. 